\title{
THE DESIGN, CONSTRUCTION AND HEAVY VEHICLE SIMULATOR TESTING RESULTS ON ROLLER COMPACTED CONCRETE TEST SECTIONS AT THE CSIR INNOVATION SITE AND ON A FULL-SCALE TEST ROAD AT RAYTON
}

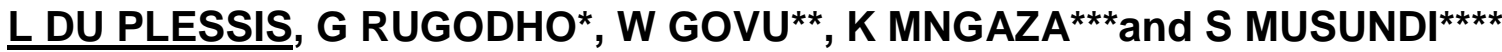

CSIR Built Environment, Meiring Naudé Street, Brummeria, Pretoria, South Africa, Phone:

+27 12841 292, Fax: +27 12842 7158, E-mail: Iplessis@csir.co.za

*Gauteng Provincial Department of Roads and Transport, Phone: 011310 2211,

E-mail: George.Rugodho@gauteng.gov.za

${ }^{* *}$ Gauteng Provincial Department of Roads and Transport, Phone: 0113102200

E-mail: Wandisile.Govu@gauteng.gov.za

${ }^{* * *}$ Gauteng Provincial Department of Roads and Transport, Phone: 0113557362

E-mail: Khuselo.Mngaza@gauteng.gov.za

**** Cosal Consultants CC, PO Box 863, De Deur, 1884, Phone: 0729332200

E-mail: cosal.steve@gmail.com

\begin{abstract}
Although the use of Roller Compacted Concrete (RCC) is not new in South Africa, the use of it to construct roads is not that well known or studied. The Gauteng Provincial Department of Roads and Transport (GPDRT) in conjunction with the CSIR Built Environment and Cosal Consultants CC started a research programme in the use of RCC technology for roads. Whereas RCC is normally constructed with a relatively low labour component using heavy mechanical equipment, one of the aims of this investigation is to evaluate the structural performance of RCC constructed with a relatively high labour component using hand-operated equipment. The evaluation was done using the Heavy Vehicle Simulator (HVS) of the GPDRT.

This paper briefly details two investigations, one conducted at the CSIR innovation site and the other test on a full-scale test road close to Rayton, Gauteng. The second investigation started in July 2013, and this paper deals mainly with the construction and initial test results of this test.

Through HVS testing it has been shown that this type of pavement performed well in the dry state, even when constructed on a substandard support system. Test results indicate that this type of pavement exceeded its predicted performance. The use of hand labour for layer compaction is discouraged as this can lead to layer densities of lower than acceptable standards which result in poor performance. The importance of proper RCC mix design to mitigate the negative effects of shrinking and crack forming is highlighted in this study.
\end{abstract}




\section{BACKGROUND}

The upgrading of unsurfaced residential roads has become a priority for many metropolitan areas in South Africa. Coupled with this is the need to construct roads using labour-intensive construction techniques. In 2007 the Gauteng Provincial Department of Roads and Transport initiated its Expanded Public Works Programme (EPWP). The goals and objectives of the EPWP are to alleviate unemployment, targeting especially women, youth and the disabled (GDID, 2007; GPG, 2007). This goal will be achieved by creating work opportunities in the following four constructive ways:

- Increasing the labour intensity of government-funded infrastructure projects;

- $\quad$ Creating work opportunities in public environmental programmes;

- $\quad$ Creating work opportunities in public social programmes, and

- Utilising general government expenditure on goods and services to provide the work experience component of small enterprise learnership/incubation programmes.

In line with these objectives the EPWP embarked on a research programme to evaluate the success of using Roller Compacted Concrete (RCC). Whereas RCC is normally constructed with a relatively low labour component and with heavy mechanical equipment, the one aim of this project is to evaluate the structural performance of RCC using a relatively high labour component and hand-operated equipment.

The investigation is conducted in phases. During the first phase a short full-scale test section was constructed at the Accelerated Pavement Testing (APT) facility of the CSIR in Pretoria. The second phase involved the construction and testing of a full-scale test pavement on an existing gravel road near Rayton, Gauteng (Route D1814). This paper details some of the initial results and analyses of these tests. As testing at Rayton is still under way (January 2014), no detail on the final results is available yet. The full testing results and analysis will be available after the completion of the current series of tests.

\section{OBJECTIVES}

The primary objective of this project is to assess the performance of RCC under real field conditions through APT coupled with a laboratory-testing programme. Comparative testing of the sections constructed by the two techniques will assist in the evaluation of labourbased RCC construction practices.

This study is aimed at building confidence in the use of RCC as a structural layer, with due cognizance being paid to pavement structure, construction, climate and traffic. 


\section{DESCRIPTION OF ROLLER COMPACTED CONCRETE}

RCC gets its name from the heavy vibratory steel drum and rubber-tired rollers used in compacting the material to its final form. RCC has similar strength properties and consists of the same basic ingredients as conventional concrete such as graded aggregates, cement and water, but with different mixture proportions (Harrington et al, 2010).

The biggest difference between RCC mixtures and conventional concrete mixtures is that $\mathrm{RCC}$ has a higher percentage of fine aggregates, which allows for tight packing, low void content and consolidation. Fresh RCC is stiffer than typical zero-slump conventional concrete. Its consistency is stiff enough to remain stable under vibratory rollers, yet wet enough to permit adequate mixing and distribution of paste without segregation. The use of RCC on roads can potentially offer multiple benefits by comparison with more conventional approaches.

RCC is typically placed with an asphalt-type paver equipped with a standard or highdensity screed, followed by a combination of passes with rollers for compaction. Final compaction is generally achieved within one hour of mixing. Unlike conventional concrete pavements, RCC pavements are constructed without forms, dowels or reinforcing steel. Joint sawing is not required, but when sawing is specified, transverse joints are spaced further apart than with conventional concrete pavements. The low water-cement ratio of RCC results in less shrinkage crack development than ordinary PCC mixes.

RCC mixtures should be dry enough to support the weight of a vibratory roller after placement, yet wet enough to ensure adequate hydration and even distribution of paste. Compaction is the process by which the aggregate particles in the RCC mixture are forced closer together, reducing the amount of air voids in the mixture and increasing the density of the layer. The increased density makes the pavement suitable in load-bearing applications. Rolling must occur before cement hydration begins to harden the paste between the aggregate particles. Achieving proper density during the rolling process helps prevent non-uniform consolidation and isolated weak areas. Depending on the specific mixture and construction equipment used, external mechanical compaction by rollers may result in a 5 to 20 per cent reduction in volume (Water resources, 2004). Minimising the air-void content in the RCC mixture is crucial to the durability of RCC. Excess air voids allow the penetration of air and water. Non-entrained air weakens the mixture, while excessive water can cause materials-related distresses in the aggregates, low field densities and insufficient early strength gain. 


\subsection{Possible Benefits}

The use of RCC on roads can potentially offer multiple benefits by comparison with more conventional approaches. The primary benefit of RCC is that it can be constructed faster and more cost-effectively than conventional concrete. Other beneficial characteristics of RCC include the following:

- The lower paste content in RCC results in less concrete shrinkage and reduced cracking from shrinkage-related stresses.

- RCC can be designed to have high flexural, compressive and shear strengths, which allow it to support heavy, repetitive loads without failure such as in heavy industrial, mining and military applications and to withstand highly concentrated loads and impacts.

- With its low permeability, RCC provides excellent durability and resistance to chemical attack, even under freeze-thaw conditions.

- $\quad$ RCC provides chemical and rut resistance in industrial areas where point loading from trailer dollies is a concern.

- Occasional light vehicles, such as cars and light trucks, can travel at low speeds on RCC pavements soon after completion without causing damage.

- Construction of RCC at ambient temperatures is suitable for labour-based construction and, hence, is ideally suited for Gauteng's EPWP.

- Apart from the basic road-building equipment (grader, roller compactor, water cart), only simple, inexpensive construction equipment is required.

- $\quad$ The existing subgrade and alignment can be used.

- $\quad$ RCC can be used as an overlay on existing roads where there is no limitation on vertical alignment.

- A significant percentage of the cement is replaced in the mix by fly-ash, a waste product from coal-fired power stations.

- RCC surfaces require less lighting energy at night than bituminous surfaces because of the reflectivity of this type of surface.

- $\quad$ Repairs of potholes and utility cuts are simple using the same material.

- Water demand is lower than that of conventional concrete, which is beneficial to the environment.

\section{METHODOLOGY FOLLOWED IN THIS STUDY}

The general methodology that was followed for the laboratory and field evaluations of the RCC mixes was as follows:

During the first phase of the project, two full-scale trial sections with a total length of approximately $65 \mathrm{~m}$ and a width of $3.6 \mathrm{~m}$ were constructed at the CSIR's innovation site. For the construction of the first section, a normal 10-ton vibratory roller was used for compaction. The second section was constructed using hand labour where compaction was done using hand-operated Bomag rollers (even for the compaction of the RCC layer). At the field test in Rayton, normal 10-ton rollers were used for the compaction of all the layers.

The RCC was subjected to a range of loading conditions and moisture regimes while being tested with the HVS in channelised, bi-direction trafficking mode in the centre of the slab (interior loading).

\section{PAVEMENT CONSTRUCTION}


The RCC test section was designed for local and provincial low-volume roads. The test pavements were designed for a Category B pavement, ES3 traffic class, 1-3 million Equivalent Standard Axles. ES3 traffic class has a maximum of $20 \%$ heavy vehicles per day over 20 years, which is approximately equal to 340 heavy vehicles per day at $1.2 \mathrm{E} 80 \mathrm{~s}$ per heavy vehicle, $50 \%$ laden and $50 \%$ unladen (Du Plessis et al, 2012). The designs for both sites (at the CSIR and Rayton) were supplied by Cosal Consultants CC.

The design specifications for the RCC test section at the CSIR site were:

- $\quad$ Subgrade: Min. CBR of 25 at 95\% Mod AASHTO, $\mathrm{Pl}<12$, Max swell 1\%;

- $\quad$ Subbase: $150 \mathrm{~mm}$ thick in-situ material compacted to $93 \%$ Mod AASHTO;

- $\quad$ Base: $150 \mathrm{~mm}$ thick G5 quality imported material stabilised with 3\% cement (of which $20 \%$ was replaced with fly-ash), compacted to $95 \%$ Mod AASHTO (to conform with $\mathrm{C} 4$ specifications), and

- RCC: $150 \mathrm{~mm}$ thick layer mix design according to consultant's specification.

The subgrade was ripped and re-compacted. After compaction, the in-situ material had an average CBR of 58 and a field density of $1788 \mathrm{~kg} / \mathrm{m}^{3}$ (94\% Mod. AASHTO), which was above the specified limit (minimum CBR of 25 at $95 \%$ Mod AASHTO).

The density of the subbase was measured with a nuclear density gauge after compaction. The subbase was only compacted to $90.7 \%$ Mod AASHTO, $2.3 \%$ short of the target density of $93 \%$ Mod AASHTO. 
For the base material, the in-situ material was used (instead of the specified G5 material) and stabilised with $2.4 \%$ cement and $0.6 \%$ fly-ash. Laboratory results indicated that after stabilisation, the base material had an unconfined compressive strength (UCS) of $244 \mathrm{kPa}$. This is lower than the acceptable standard for a South African C4 type stabilised base with a specified minimum UCS of $750 \mathrm{kPa}$ (CSRA, 1985). The field compaction was $92.3 \%$ Mod AASHTO, which was also lower than the specified minimum limit of $95 \%$.

The RCC layer was constructed with river sand and $9.5 \mathrm{~mm}$ crushed quartzite stone. The mix design consisted of cement : sand : stone ratio of $1: 2: 3$. As in the case of the stabilised base, $20 \%$ of the cement content was replaced by fly-ash. A CEM III A 32,5 N cement was specified. Apart from the fly-ash, no other type of additive or air entrainment agent was used.

The design specifications for the RCC test section at the Rayton site were (Du Plessis et al, 2013):

- $150 \mathrm{~mm}$ RCC;

- 150 mm C4 base material (G5 parent material) compacted to 97\% Mod AASHTO;

- 150 mm G5 upper select subbase compacted to 95\% Mod AASHTO;

- 150 mm G5 lower select subbase compacted to 93\% Mod AASHTO, and

- $125 \mathrm{~mm}$ G7 fill compacted to $90 \%$ Mod AASHTO.

The subgrade investigation revealed that the top $150 \mathrm{~mm}$ should be reworked and compacted to at least G9 material quality in order to satisfy the design requirements for a ES1 to ES10 pavement design (between 300000 and 10 million equivalent $80 \mathrm{kN}$ standard axles).

The RCC mix design as supplied by Cosal Consultants CC was:

- CEM II $32.5 \mathrm{~N}$ : $12.2 \%$

- Fly-ash: $5.2 \%$

- Sand: $45.4 \%$

- $13 \mathrm{~mm}$ stone: $\quad 37.2 \%$

- Water/Cement ratio: 0.53

The as-built pavement conformed to the design specifications with small variations. The concrete was supplied by a ready-mix supplier and no information on the true field mix was made available for evaluation.

\section{HVS RESULTS}

\section{1 $\quad$ HVS test 467A5 RCC placed with mechanical equipment}

The section was tested in a dry state under a standard half-axle load of $40 \mathrm{kN}$ for one million repetitions after which it was increased to $60 \mathrm{kN}$ until failure. The test pad was selected in such a way that the HVS testing wheel ran over a shrinkage crack as this was considered to be the weakest area in the test section (Du Plessis et al, 2012). The pavement failed after 1.8 million repetitions, which equates to 5.4 million E80s using the accepted exponential damage factor of 4.2. This surpasses the design life of the pavement which is between 1 and 3 million E80s. 


\subsubsection{Elastic deflection response}

The variations in the elastic deflections (Figure 1) are mainly due to daily temperature variations and the increase load to $60 \mathrm{kN}$ after a million repetitions. The sudden drop in deflection at approximately 1.6 million repetitions is the result of additional crack formation around the instrumented shrinkage crack. Multi-Depth Deflectometer (MDD) data indicated that most of the deflections originated between the surface and the base $(200 \mathrm{~mm}$ from the surface). Figure 1 shows both the surface deflections captured by the Joint Deflection Measuring Devices (JDMDs) and MDD in-depth deflections. Both instruments (MDD and JDMD) recorded increasing deflections downwards (although presented differently in the figure).

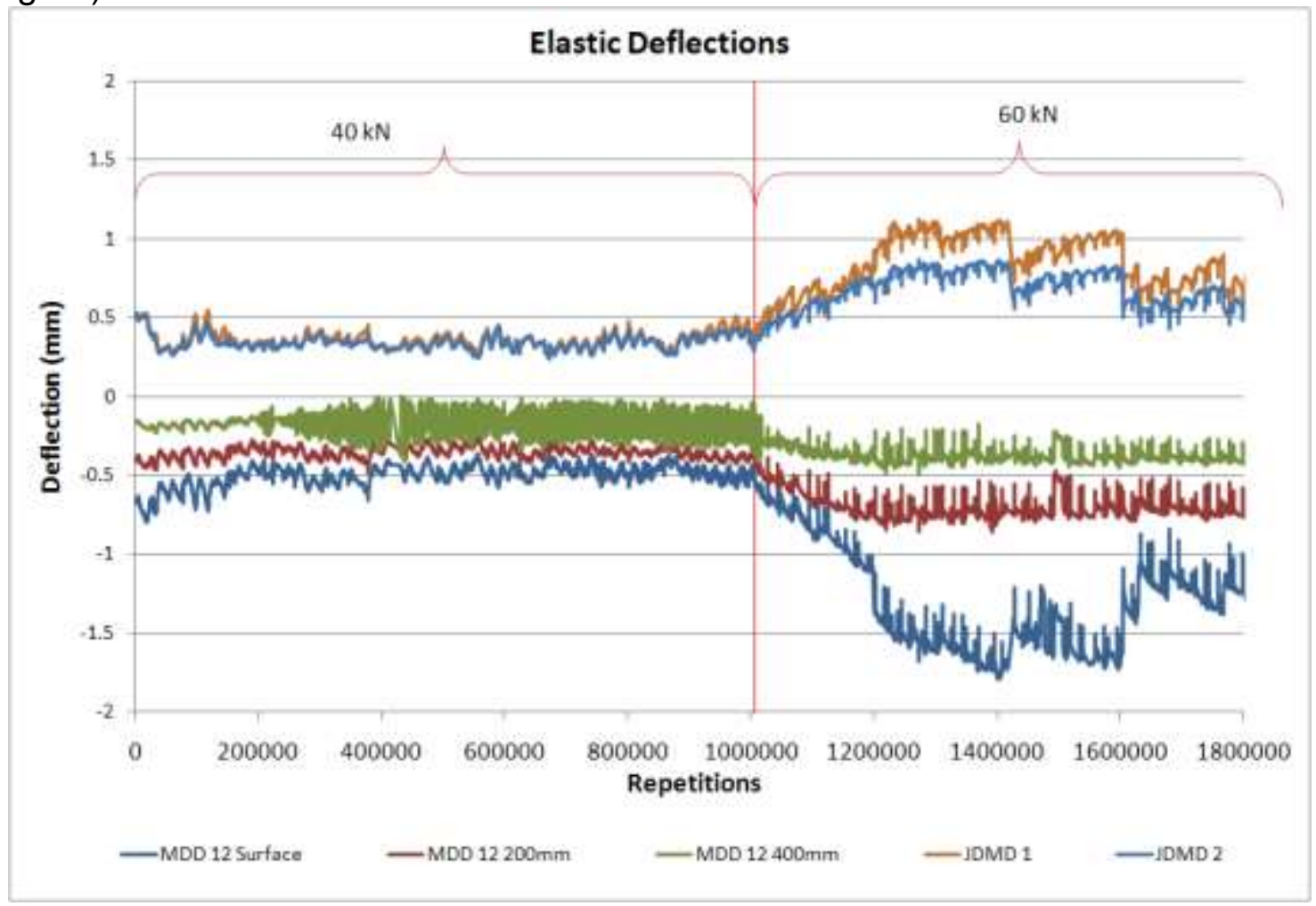

Figure 1: Elastic deflections

It is obvious that a significant degree of separation between the bottom of the concrete and the top of the base occurred during the $60 \mathrm{kN}$ cycle. MDD deflections on the surface were higher than $1.7 \mathrm{~mm}$ in comparison with base deflections where the maximums were lower than $0.8 \mathrm{~mm}$.

\subsubsection{Load-transfer efficiency and relative movement}

Load-Transfer Efficiency (LTE) and Relative Movements (RM) across the shrinkage crack are shown in Figure 2. LTE indicates the efficiency with which the load is transferred across a crack. It is defined as the relationship between deflection of the unloaded slab $\left(\Delta_{U}\right)$ and the deflection of the loaded slab $\left(\Delta_{\mathrm{L}}\right)$ or:

$\operatorname{LTE}(\%)=\Delta_{U} / \Delta_{\mathrm{L}} \times 100$

An LTE of $100 \%$ is consistent with full load-transfer, and an LTE of $0 \%$ indicates zero load transfer.

RM is the movement of the loaded slab $\left(\Delta_{\mathrm{L}}\right)$ relative to the movement of the unloaded slab $\left(\Delta_{U}\right)$, or:

$\mathrm{RM}(\mathrm{mm})=\Delta_{\mathrm{L}}-\Delta_{\mathrm{U}}$ 
An $\mathrm{RM}$ of $0 \mathrm{~mm}$ indicates that both the loaded and unloaded slabs had the same reaction to the applied load and correspond to an LTE of $100 \%$.

By considering the above two parameters, it is possible to quantify the effectiveness of the load transferred through pavement deflection across a crack or a joint. The LTE was relatively high (above $80 \%$ ) during the first 800000 repetitions, with a maximum $\mathrm{RM}$ of approximately $0.2 \mathrm{~mm}$. The LTE dropped to below $70 \%$ after the load was increased to 60 $\mathrm{kN}$, after which it remained fairly constant. The RM ranged between $0.25 \mathrm{~mm}$ and $0.4 \mathrm{~mm}$. This drop in LTE signifies a significant loss in aggregate interlock across the shrinkage crack after the application of approximately 1.2 million load applications.

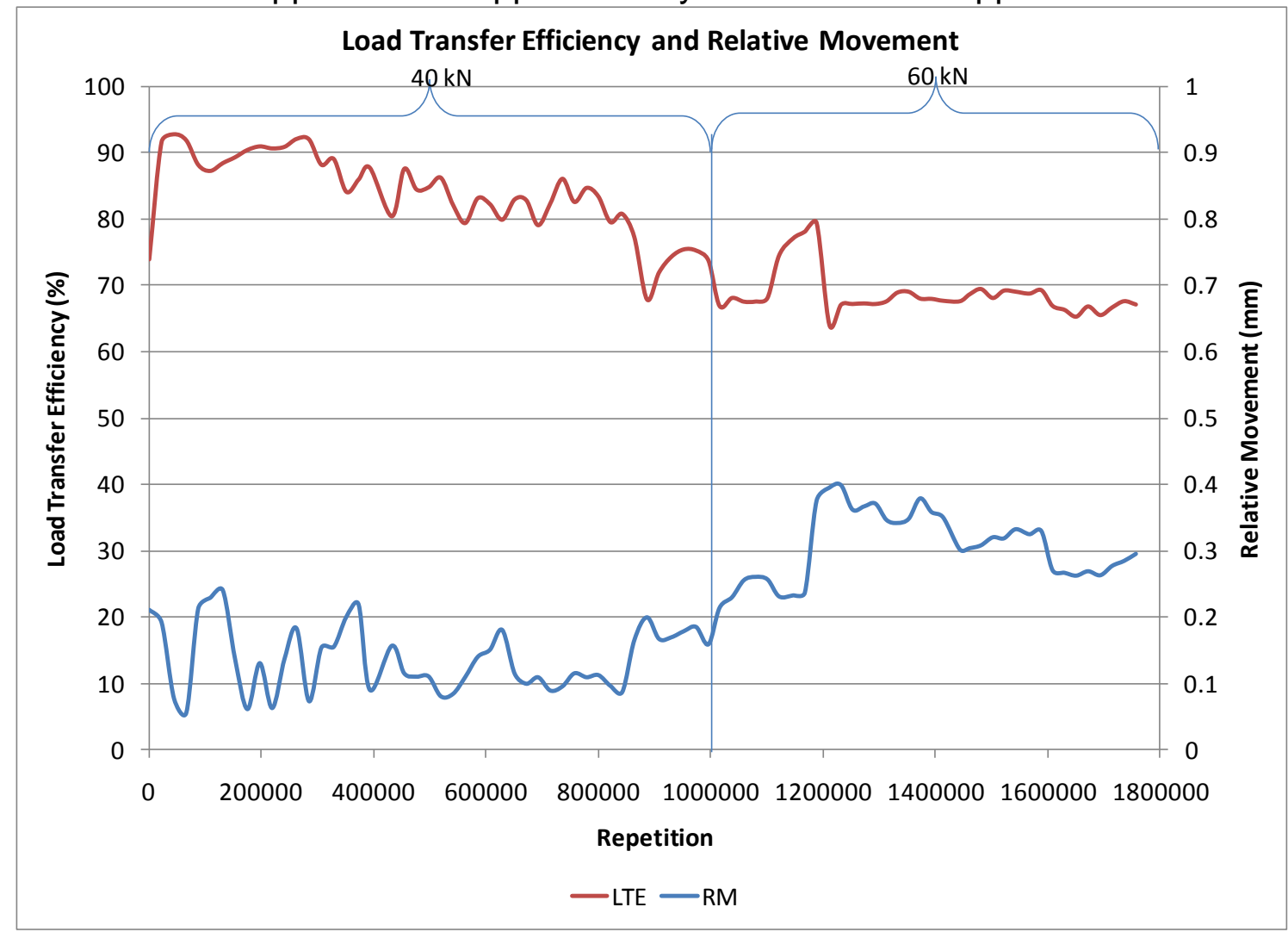

Figure 2: Load-transfer efficiency and relative movement

\subsubsection{Permanent deformation}

Concrete pavements do not traditionally fail in rutting, but due to the weak substructure, the layers experienced a significant amount of permanent deformation in the granular layers. The permanent deformation recorded by both JDMDs and MDD is illustrated in Figure 3. Similar to the deflection figure (Figure 1), both instruments recorded increasing deformation downwards (although presented differently in the figure). Surface deformation of over $12 \mathrm{~mm}$ was recorded at the end of the test. This caused the slab to crack up to the extent that no further testing was possible. 


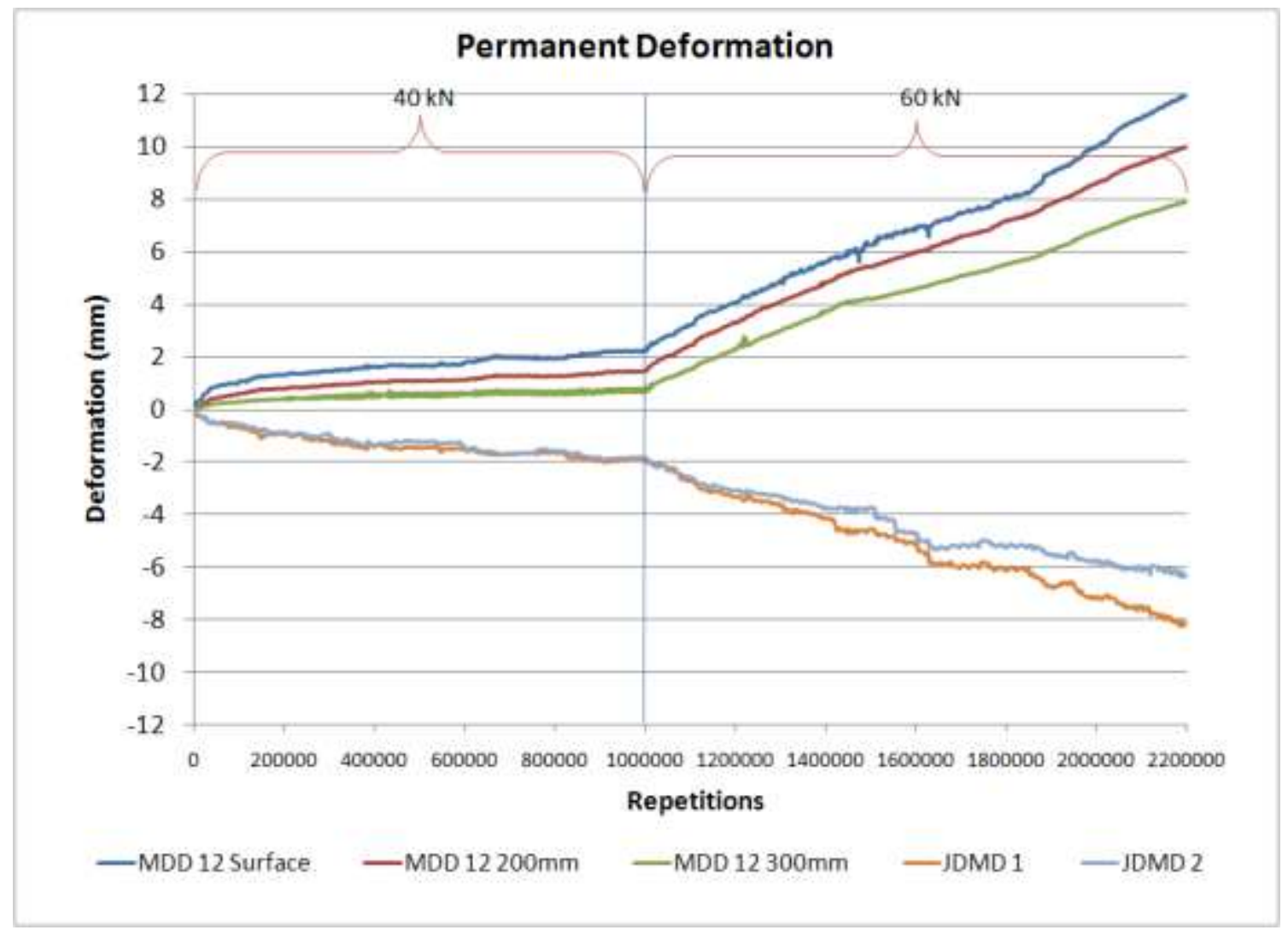

\section{Figure 3: Permanent deformation}

\subsection{HVS test 468A5 hand-constructed RCC section}

Test 469A5 was the first test conducted on the labour-intensive constructed section. Testing was done in both the dry and wet states to simulate the effects of dry and wet periods. The dry/wet cycles were based on five days of trafficking under dry conditions, followed by two days of trafficking under wet conditions, this cycle then being repeated until failure (Du Plessis et al, 2012). Water was introduced from 227500 repetitions onwards. Testing started on 27 June 2011 and was completed after 609036 repetitions when the section was considered to have failed. The section lasted for three wet cycles and failed within 37000 dry repetitions after completion of the third wet cycle. Significant degree of pumping was observed during the wet cycles which caused cavities under the concrete and resulted in high surface deflections and ultimate early failure of the section.

Reasons for the poor performance include:

- The subbase layer was not compacted properly as detailed in Section 5.

- The base layer (C4) was not constructed at optimum moisture content. Although the laboratory mix design suggested that the optimum moisture content should be $6.9 \%$, the field mix moisture content was on average between $3.08 \%$ and $3.3 \%$. This low water content negatively influenced the ability of the cement in the granular material to hydrate properly and lower strengths were achieved than theoretically possible. The cemented material had an average UCS value of $245 \mathrm{kPa}$ at field moisture contents. This value is lower than that prescribed for a $\mathrm{C} 4$ type of cemented base material (Du Plessis et al, 2012) and the layer. 
- RCC layer: The average thickness of the concrete layer was $145 \mathrm{~mm}$ instead of the prescribed $150 \mathrm{~mm}$. The maximum strength of the field mix was $15.63 \mathrm{MPa}$ (28-day strength). This is less than that expected from CEM III 32.5 cement. Another possible reason may be insufficient compaction of the RCC. Samples cored from the section showed big voids in the RCC. A picture showing the failure is presented in Figure 4.

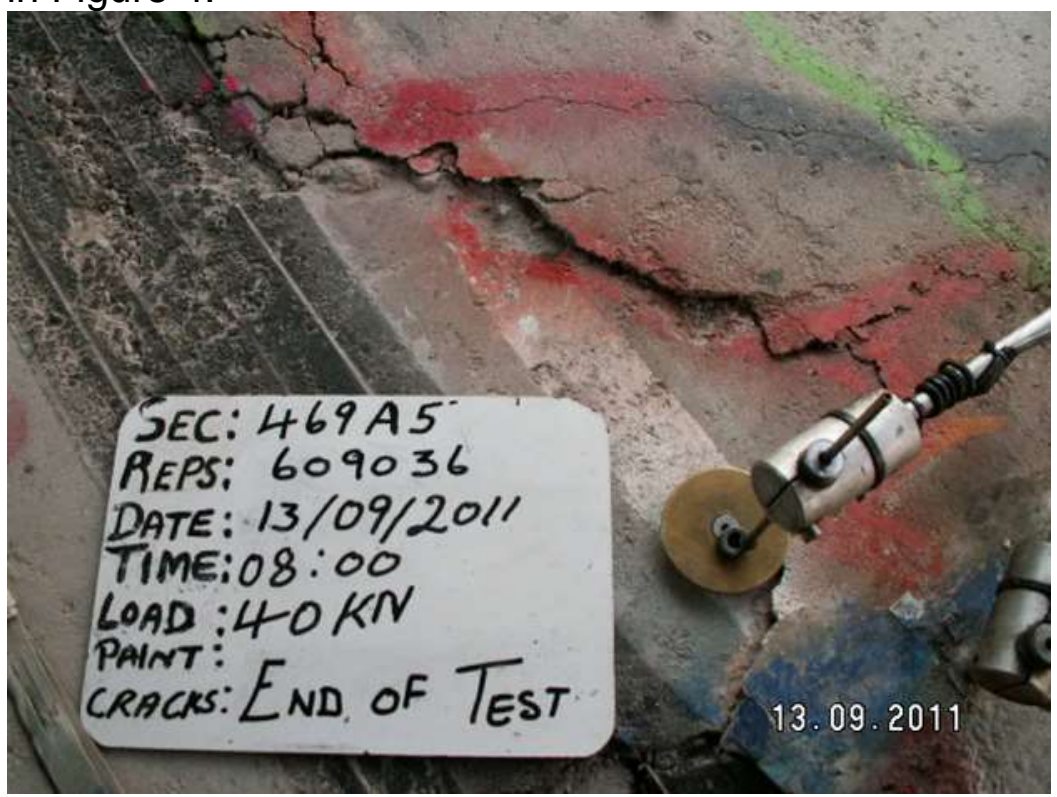

Figure 4: Failure after 609036 repetitions on the hand-constructed RCC layer

\subsection{HVS test 470A5 RCC constructed at Rayton}

Because the test has not been completed, only provisional results are presented here (Du Plessis et al, 2013). The HVS test pad with respect to the $100 \mathrm{~m}$ test section is shown in Figure 5.

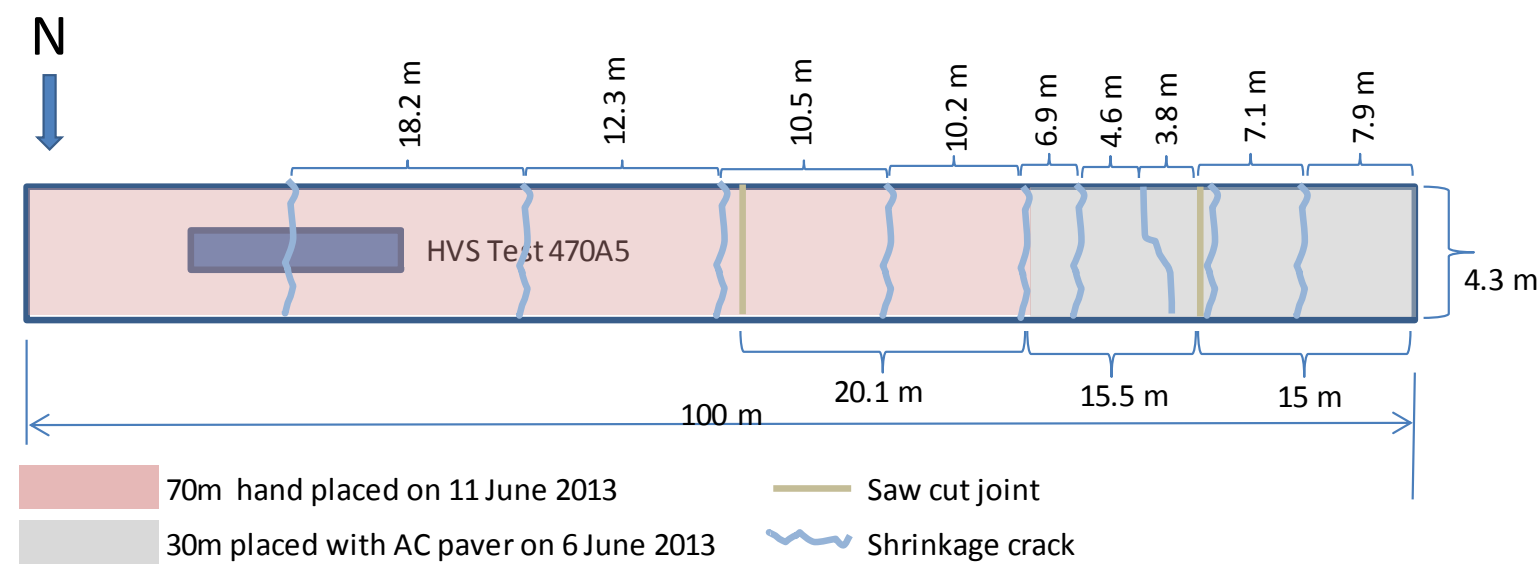

Figure 5: HVS test pad placed across a shrinkage crack (no to scale)

The HVS was positioned over the first shrinkage crack which appeared within 10 days of construction approximately $19 \mathrm{~m}$ from the eastern end of the $100 \mathrm{~m} \mathrm{RCC}$ test section. The other shrinkage cracks can also be seen in Figure 5. It should be noted that the first $30 \mathrm{~m}$ (the grey shaded area on the right-hand side in the figure) was constructed with the aid of an asphalt paver, the remaining $70 \mathrm{~m}$ being placed 5 days later using hand labour and a 10-ton vibrating compaction roller. Ready-mix concrete was used for the whole $100 \mathrm{~m}$ section. 
The first 1.207 million repetitions were done in the dry state using a $40 \mathrm{kN}$ load (simulating an $80 \mathrm{kN}$ standard axle load). Testing is still continuing and a total of $2000000 \mathrm{bi}$ directional repetitions was achieved by November 2013. Because of the slow rate of deterioration, the load was increased to $60 \mathrm{kN}$ (simulating a 50\% overload) from 1.207 million repetitions onwards. In addition to this, water was introduced to the surface from 1.76 million repetitions onwards. The water was applied in the same manner as the previous RCC test. Using the 4.2 exponential power damage law, a total of 5.592 million standard $80 \mathrm{kN}$ axle loads had been applied without any signs of visual damage. This meets requirements of an ES3 design class (between 1 million and 3 million E80s).

The surface and in-depth deflections as measured by the MDDs are shown in Figure 6 . The surface deflections are unrealistically high (over $1.6 \mathrm{~mm}$ ) in the vicinity of the shrinkage crack and the surface deflections away from the crack (not shown in the figure) are low (less than $0.1 \mathrm{~mm}$ ). The conclusion is that a significant amount of permanent slab warping occurred at the shrinkage crack, which caused the concrete to separate from the base. This conclusion is substantiated by the in-depth deflections as recorded by the MDD modules placed in the base $(170 \mathrm{~mm})$ and subbase $(330 \mathrm{~mm})$. The deflection module placed at the top of the base (at $170 \mathrm{~mm}$ in depth) recorded virtually zero deflections in comparison with the surface deflections (over $1.6 \mathrm{~mm}$ ). It is obvious that the area surrounding the crack is structurally in a poor state in comparison with the rest of the testing area.

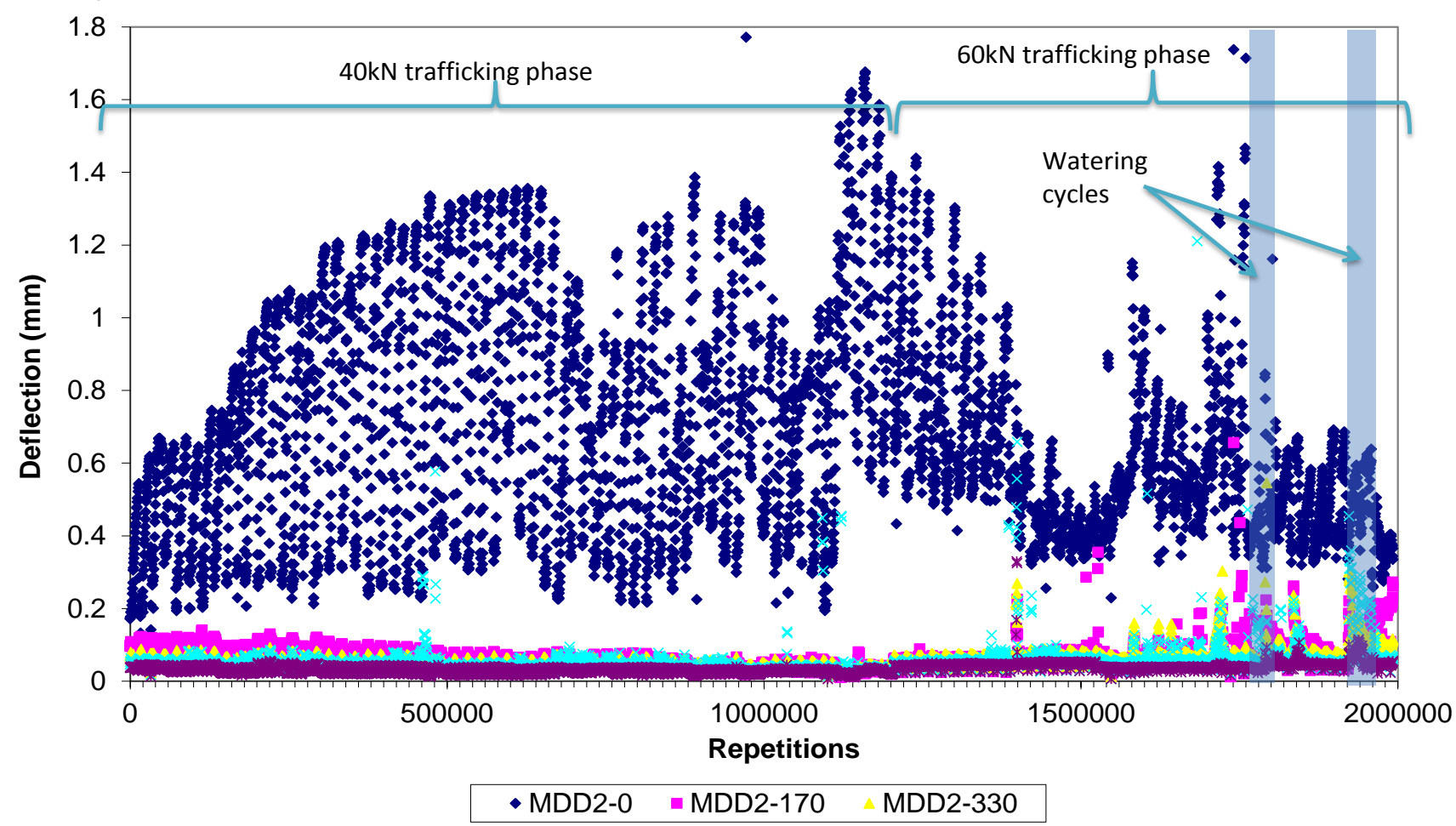

Figure 6: MDD surface and in-depth deflections 
LTE was also investigated at the crack (Figure 7). The figure shows the deflection bowls captured by two JDMD instruments placed opposite each other, across the shrinkage crack. After 580000 repetitions, a significant drop in the load transfer can be seen.

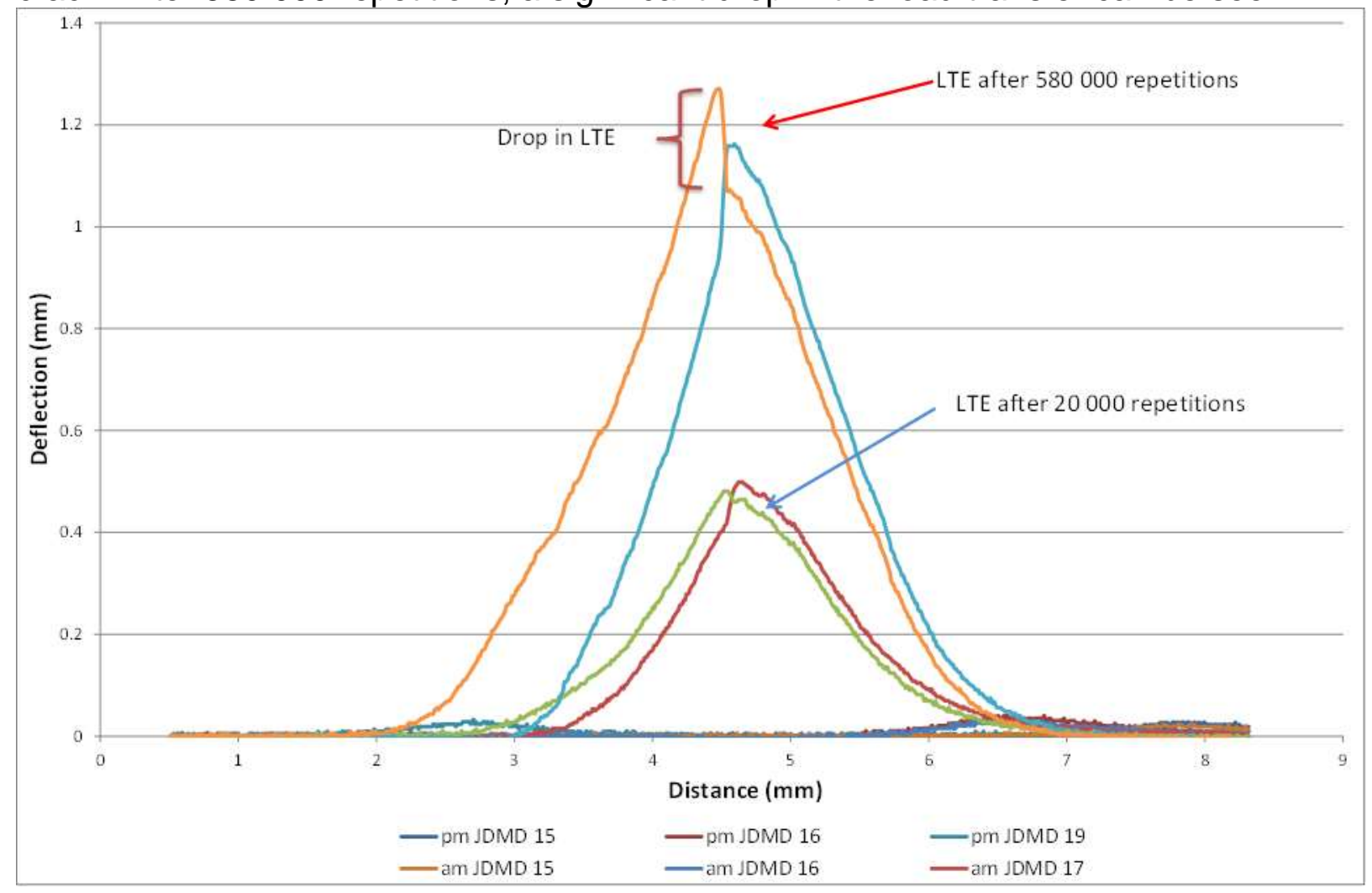

Figure 7: Deflection bowls showing the drop in load-transfer efficiency across a shrinkage crack 


\section{CONCLUSIONS AND RECOMMENDATIONS}

This paper summarises the most significant results and findings of three HVS tests done on RCC pavement structures. Although the sections have lasted their design life, the differences in the behaviour at shrinkage cracks in comparison with uncracked areas are of concern. The importance of proper design of all the pavement layers is highlighted in this study. Deviations from the design specifications can lead to costly early failures. To meet the performance requirements, the RCC layer should be placed on top of a welldesigned base course material which should not be water-sensitive should water enter the pavement though surface cracks. Long-life pavement performance of concrete type structures is governed, inter alia, by the following four important guiding principles:

1. The concrete should be designed in such a way that any uncontrolled shrinkage cracks are sufficiently small to ensure that good aggregate interlock is maintained and that the ingress of water into the lower layers is prevented.

2. The loss of material as a result of pumping should be minimised through the above mentioned principle, as well as through proper design of the base course in order to ensure that the material has sufficient resistance against water erosion.

3. The surface deflections should be as low as possible to prevent hydraulic action which causes pumping of the support material under the influence of traffic and water.

4. In addition to this, it should be realised that temperature plays an important role in the performance of concrete pavements and that any concrete mix should be designed to withstand the build-up of stresses resulting from changes in temperature and temperature gradients within the concrete.

\section{ACKNOWLEDGEMENTS}

This HVS research project is supported by the Gauteng Provincial Department of Roads and Transport and their financial and technical contribution towards this study is greatly acknowledged. The authors thank Mr Steve Musundi, the managing director of Cosal Consultants CC, who did the foundational work, was responsible for the design and construction and provided input during the execution of this research programme. 


\section{REFERENCES}

Committee of State Road Authorities. Guidelines for Road Construction Materials, TRH 14. Pretoria, 1985.

Du Plessis, L., Louw, S., Fisher, C. and Leyland, R. First Level Analysis Report: HVS Testing of Roller Compacted Concrete Test 467A5 - 469A5. CSIR contract report, July, 2012.

Du Plessis, L., Fisher, C. and Leyland, R. HVS testing of Roller Compacted Concrete on Road D1814, Cullinan: Draft Preliminary Report. CSIR contract report, December, 2013.

Framework for Monitoring and Evaluation of the Expanded Public Works Programme, Publication of the Gautrans Provincial Government, June 2007.

Gauteng Province Department of Infrastructure Development. Web page: http://www.did.gpg.gov.za/Pages/GEPWPBackground.aspx_ 2007

Harrington, D., Abdo, F., Adaska, W. and Hazaree, C. 2010. Guide for roller-compacted concrete pavements. National Concrete Pavement Technology Center, lowa State University.

Water resources. 2004. Roller-Compacted Concrete Density: Principles and Practices. Skokie, Illinois: Portland Cement Association. 